\title{
Small Cell Carcinoma of the Esophagus: A Case Report
}

\author{
Ichiro Akagi ${ }^{1,2}$, Masao Miyashita ${ }^{1}$, Hiroshi Makino ${ }^{1}$, Tsutomu Nomura ${ }^{1}$, \\ Kimiyoshi Shimanuki', Shuichi Satake ${ }^{2}$, Nobutoshi Hagiwara ${ }^{1}$ and Eiji Uchida ${ }^{1}$ \\ ${ }^{1}$ Department of Gastrointestinal and Hepato-Biliary-Pancreatic Surgery, Nippon Medical School \\ ${ }^{2}$ Department of Surgery, Aizu Central Hospital
}

\begin{abstract}
A case of esophageal small cell carcinoma successfully treated with combination therapy consisting of preoperative chemotherapy, radiation therapy, and surgical resection. A 76-yearold man presented with a small cell carcinoma measuring $6 \mathrm{~cm}$ in diameter in the middle third of the thoracic esophagus. After preoperative therapy, the gross tumor was completely resected. The patient eventually died of metastatic disease 25 months after diagosis. We discuss the treatment of esophageal small cell carcinoma.
\end{abstract}

(J Nippon Med Sch 2014; 81: 97-100)

Key words: small cell carcinoma, esophageal carcinoma, esophagectomy

\section{Introduction}

Small cell carcinoma is a distinct entity first described in the lung. The occurrence of primary intrapulmonary tumors has been described in other organs. Primary small cell carcinoma of the esophagus, which is similar in appearance and behavior to its counterpart of the lung, is rare. Most patients relapse after dissemination of the disease and have a poor prognosis. ${ }^{1}$. The management of small cell carcinoma of the esophagus is not well defined because of the small number of reported cases. We report on a patient with advanced small cell carcinoma of the esophagus treated with radiation therapy (total dose, $31.5 \mathrm{~Gy}$ ), combination chemotherapy with cisplatin and etoposide, and surgical resection.

\section{Case Report}

A 76-year-old man had complained of dysphagia during ingestion of solids for 2 months and consulted his family doctor. A barium ingestion test revealed a mass in the middle third of the thoracic esophagus. He was then referred to our department. He was not a habitual smoker, and no abnormalities were found on physical examination. Routine laboratory data were within normal limits. A pretreatment barium esophagram revealed a $6-\mathrm{cm}$ mass with central ulceration in the middle third of the thoracic esophagus (Fig. 1). Endoscopic examination also showed an esophageal tumor with the same configuration. The histologic features of a biopsy specimen obtained from the tumor during endoscopy were consistant with small cell carcinoma. A computed tomographic scan revealed abnormal thickening of the middle esophageal wall,

Correspondence to Ichiro Akagi, MD, PhD, Department of Gastrointestinal and Hepato-Billary-Pancreatic Surgery,

Nippon Medical School, 1-1-5 Sendagi, Bunkyo-ku, Tokyo 113-8603, Japan

E-mail: ichiro@nms.ac.jp

Journal Website (http://www.nms.ac.jp/jnms/) 


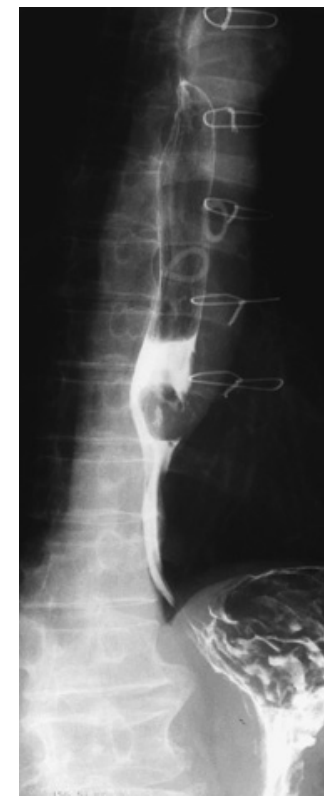

Fig. 1 A pretreatment barium esophagram revealed a 6-cm mass with central ulceration in the middle third of the thoracic esophagus.

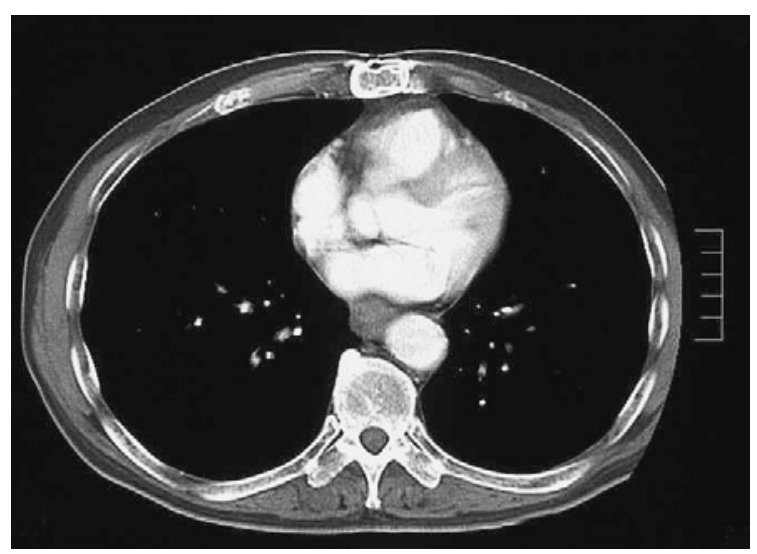

Fig. 2 Computed tomography revealed abnormal thickening of the middle esophageal wall, but no metastatic disease was evident in the mediastinal lymph nodes or liver.

but no metastatic disease was evident in the mediastinal lymph nodes or liver (Fig. 2).

After small cell carcinoma of the esophagus was diagnosed, the patient underwent chemotherapy. The regimen consisted of cisplatin, $80 \mathrm{mg} / \mathrm{m}^{2}$ on day 1 , and etoposide, $100 \mathrm{mg} / \mathrm{m}^{2}$ on days 1 to 3 . The patient also received radiation of the tumor and regional lymph nodes with a total dose of $31.5 \mathrm{~Gy}$. After neoadjuvant therapy, a partial response was achieved, as shown by barium esophagram (Fig. 3)

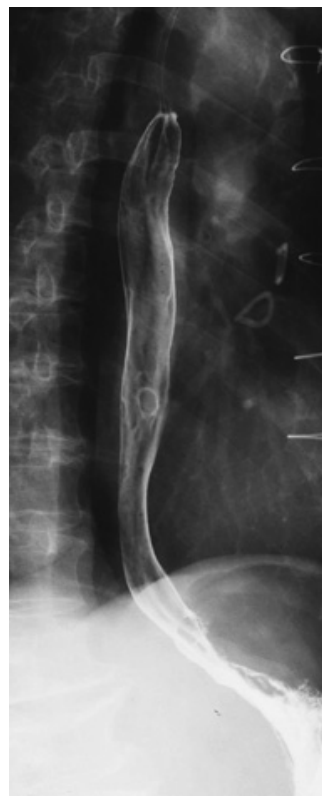

Fig. 3 After neoadjuvant therapy, a barium esophagram showed an elevated tumor with ulceration which achieved a partial response.

and esophagogastroendoscopy

(Fig. 4A, 4B).

Curative esophagectomy with lymph node dissection was then performed. The patient's postoperative course was uneventful. However, he eventually died of metastatic disease 25 months after diagnosis.

Pathological examination indicated that the tumor had not invaded the muscle layer (T1, invading the submucosa), and only 1 metastatic lymph node was found (pT1N1M0, pStage IIB). The resected specimen had a shallow ulceration in the middle-tolower esophagus with no gross evidence of a residual tumor (Fig. 5A). The tumor was a small cell carcinoma with cells arranged in a cord-like configuration and no evidence of squamous or glandular features (Fig. 5B). Histochemical studies showed that the tumor cells were positive for synaptophysin and CD56 but negative for chromogranin A.

\section{Discussion}

Small cell esophageal carcinoma (SCEC) is a rare neoplasm ${ }^{2.3}$. Although the rarity of this tumor has impeded statistical evaluation, SCEC has a poor prognosis because of its aggressive biologic behavior and early widespread dissemination ${ }^{2.3}$. The main 

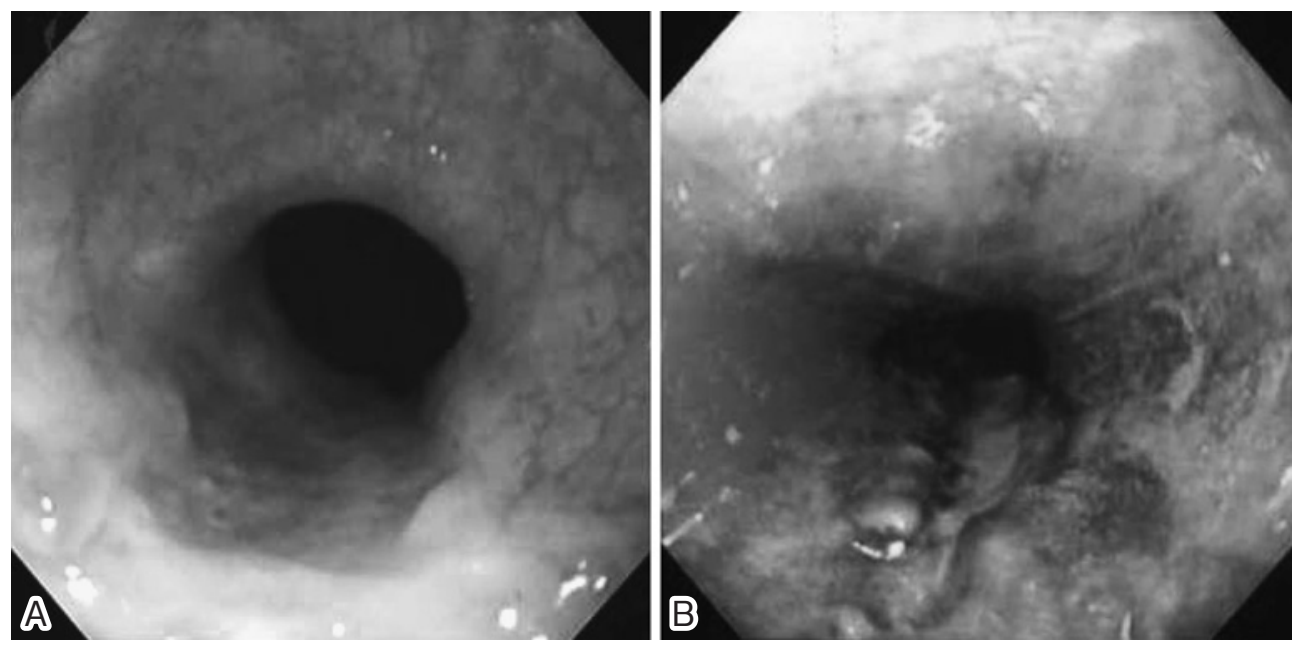

Fig. 4 Esophagogastroendoscopy revealed an elevated lesion with excavative ulceration on the posterior wall of the esophagus (A) and a Lugol-unstained lesion (B).
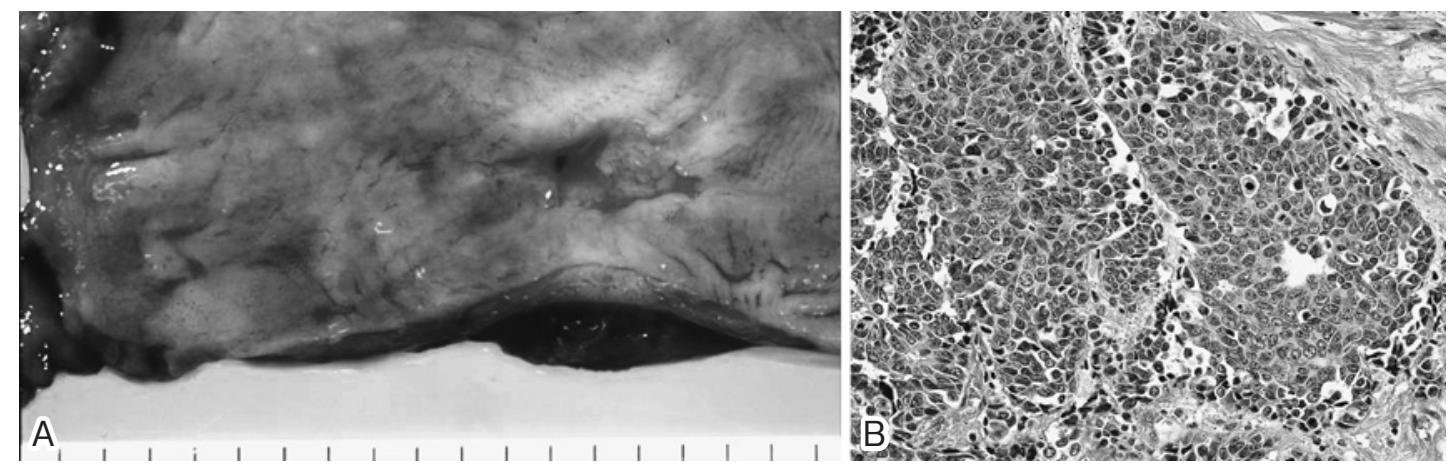

Fig. 5 The resected specimen had a shallow ulceration in the middle-to-lower esophagus with no gross evidence of a residual tumor (A). The tumor was a small cell carcinoma with cells arranged in a cord-like configuration and no evidence of squamous or glandular features (B).

symptoms are rapidly progressive dysphagia and weight loss, which are usual for esophageal cancer.

Small cell carcinoma is histologically defined by small spindle-shaped or polygonal tumor cells with hyperchromatic nuclei and scanty cytoplasm. The neuroendocrine character of SCEC has been reported because of the presence of intracytoplasmic argyrophilia and neurosecretory granules occasionally observed with Grimelius staining and electron microscopy, respectively. However, such neuroendocrine characteristics are not required for the diagnosis of $\mathrm{SCEC}^{4-7}$ and were not present in the present case. Moreover, tumor tissue in cases of SCEC frequently includes squamous cell carcinoma or adenocarcinoma $a^{5-10}$, and components of squamous cell carcinoma have been found in more than $20 \%$ of patients with $\mathrm{SCEC}^{5-11}$. In the present patient, the microscopic tumor foci remaining after preoperative chemotherapy were exclusively small cell carcinoma without squamous cell carcinoma. Fulminant systemic spread has been reported to be a common characteristic of SCEC. Johnson et al. have reported that the calculated tumor doubling time in their patients with SCEC was approximately 2 days ${ }^{12}$. Because of this rapid growth, the prognosis of SCEC is extremely poor. McFadden et al. have reviewed the literature and reported that the median survival of patients with SCEC was 7.8 months, whereas our patient survived 25 months.

Various treatments, including surgery, chemotherapy, and radiotherapy, have been used in an attempt to prolong the survival of patients with SCEC. In recent reports, regimens including cisplatin have achieved better responses. Tanebe et al. have 
reported that of regimens with 5 anticancer drugs (cisplatin, etoposide, vincristine, doxorubicin, and cyclophosphamide), those including cisplatin and etoposide were most effective ${ }^{13}$. Radiation therapy is effective, as in small cell carcinoma of the lung, but because it is only a local control therapy, radiation alone is not an appropriate initial treatment.

Surgery as the primary treatment for small cell carcinoma of the lung was abandoned because of the results of the British Medical Council studies of the 1960s comparing primary radiation therapy with surgery ${ }^{14,15}$. The same tumor of the esophagus has been considered similarly. However, several studies have shown long-term survival after surgery as a local therapy for SCEC. One patient in the series reported by Law et al. survived more than 5 years after surgery ${ }^{16}$. Nishimaki et al. reported on 2 longterm survivors treated with esophagectomy for limited disease; 1 patient survived 106 months, and the other patients survived 64 months $^{17}$. They described the important role of esophagectomy in the treatment for locoregional SCEC. Craig et al. have reported a mean survival of 20 months in 7 patients treated with esophagectomy with or without adjuvant therapy ${ }^{18}$. Medgyesy et al. have reported 4 cases of limited disease treated with surgery after preoperative chemotherapy with or without radiotherapy ${ }^{19}$. These reports of long-term survival after surgery suggest that surgery is an effective means of local control in combination therapy for SCEC.

In conclusion, SCEC, like small cell carcinoma of the lung, has, for more than 3 decades, been considered a disease for which surgery is not a primary treatment. We now believe radical esophagectomy could be included within a protocol as the treatment of choice for selected patients with SCEC, especially for patients with clinically limited disease.

Conflict of Interest: The authors declare no conflict of interest.

\section{References}

1. Tennvall J, Johansson L, Albertsson M: Small cell carcinoma of the oesophagus: a clinical and immunohistopathological review. Eur J Surg Oncol 1990; 162: 109-115.

2. Huncharek M, Muscat J: Small cell carcinoma of the esophagus. The Massachusetts General Hospital experience, 1978 to 1993 . Chest 1995; 1071: 179-181.

3. Pantvaidya GH, Pramesh CS, Deshpande MS, Jambhekar NA, Sharma S, Deshpande RK: Small cell carcinoma of the esophagus: the Tata Memorial Hospital experience. Ann Thorac Surg 2002; 746: 1924-1927.

4. McFadden DW, Rudnicki M, Talamini MA: Primary small cell carcinoma of the esophagus. Ann Thorac Surg 1989; 47: 477-480.

5. Ho KJ, Herrera GA, Jones JM, Alexander CB: Small cell carcinoma of the esophagus: evidence for a unified histogenesis. Hum Pathol 1984; 155: 460-468.

6. Reyes CV, Chejfec G, Jao W, Gould VE: Neuroendocrine carcinomas of the esophagus. Ultrastruct Pathol 1980; 13: 367-376.

7. Reid HA, Richardson WW, Corrin B: Oat cell carcinoma of the esophagus. Cancer 1980; 459: 23422347.

8. Briggs JC, Ibrahim NB: Oat cell carcinomas of the oesophagus: a clinico-pathological study of 23 cases. Histopathology 1983; 72: 261-277.

9. Cook MG, Eusebi V, Betts CM: Oat-cell carcinoma of the oesophagus: a recently recognized entity. J Clin Pathol 1976; 2912: 1068-1073.

10. Sasajima K, Hayashi N, Yamashita K, Onda M, Takubo K: Oat cell carcinoma of the esophagus with multiple differentiation. J Clin Gastroenterol 1988; 106: $667-671$

11. Mori M, Matsukuma A, Adachi Y, et al.: Small cell carcinoma of the esophagus. Cancer 1989; 633: 564573.

12. Johnson FE, Clawson MC, Bashiti HM, Silverberg $\mathrm{AB}$, Broun GO Jr: Small cell undifferentiated carcinoma of the esophagus. Case report with hormonal studies. Cancer 1984; 538: 1746-1751.

13. Tanabe G, Kajisa T, Shimazu H, Yoshida A: Effective chemotherapy for small cell carcinoma of the esophagus. Cancer 1987; 6011: 2613-2616.

14. Miller AB, Fox W, Tall R: Five-year follow-up of the Medical Research Council comparative trial of surgery and radiotherapy for the primary treatment of small-celled or oat-celled carcinoma of the bronchus. Lancet 1969; 27619: 501-505.

15. Fox W, Scadding JG: Medical Research Council comparative trial of surgery and radiotherapy for primary treatment of small-celled or oat-celled carcinoma of bronchus. Ten-year follow-up. Lancet 1973; 27820: 63-65.

16. Law SY, Fok M, Lam KY, Loke SL, Ma LT, Wong J: Small cell carcinoma of the esophagus. Cancer 1994; 7312: 2894-2899.

17. Nishimaki T, Suzuki T, Nakagawa S, Watanabe K, Aizawa K, Hatakeyama K: Tumor spread and outcome of treatment in primary esophageal small cell carcinoma. J Surg Oncol 1997; 642: 130-134.

18. Craig SR, Carey FA, Walker WS, Cameron EW: Primary small-cell cancer of the esophagus. J Thorac Cardiovasc Surg 1995; 1092: 284-288.

19. Medgyesy CD, Wolff RA, Putnam JB Jr, Ajani JA: Small cell carcinoma of the esophagus: the University of Texas M. D. Anderson Cancer Center experience and literature review. Cancer 2000; 882: 262-267. 